\title{
Alterações bioquímicas de plantas e morfológicas de gemas de cafeeiro associadas a eventos do florescimento em resposta a elementos meteorológicos
}

\author{
Biochemical alterations of plants and bud morphology of coffee tree associated to events on \\ flowering in response to meteorological elements
}

\author{
Marilza Neves do Nascimento ${ }^{\mathrm{I}^{*}}$ José Donizeti Alves $^{\mathrm{I}}$ Ângela Maria Soares ${ }^{\mathrm{I}}$ \\ Evaristo Mauro de Castro' ${ }^{I}$ Marcelo Murad Magalhães ${ }^{I}$ Amauri Alves de Alvarenga ${ }^{I}$ \\ Guilherme Henrique Silva
}

\section{RESUMO}

O florescimento do cafeeiro envolve diversos fatores, tanto da planta como do ambiente. A compreensão das interações entre esses fatores pode contribuir para o desenvolvimento de práticas de manejo mais dequadas, principalmente em relação à irrigação. Tais práticas podem vir a promover uma uniformização da floração, conseqüentemente uniformização da maturação dos frutos, minimizando os custos de produção. O objetivo deste trabalho foi avaliar alterações morfológicas de gemas, síntese de prolina $e$ de ácido abscísico em plantas de cafeeiros em resposta a elementos meteorológicos, visando assim contribuir para o conhecimento de fatores que influenciam a uniformização da floração. Foram feitas análises, por meio de técnicas de microscopia eletrônica de varredura, em gemas de ramos plagiotrópicos de primeira ordem, coletadas semanalmente durante o período de novembro/04 a fevereiro/05. No período de julho a setembro de 2005, foram realizadas avaliações em plantas irrigadas e não-irrigadas, de potencial hídrico foliar antes do amanhecer e teor de prolina, em folhas totalmente expandidas, posicionadas em ramos do terço superior da copa. Foi também avaliado o teor de ácido abscísico na seiva do xilema e nas gemas florais. Os resultados mostram modificações na estrutura das gemas associadas a um período de déficit hídrico seguido de precipitação e, conseqüentemente, de menor amplitude térmica. Em relação ao potencial hídrico, há diferenças entre os tratamentos irrigado e não-irrigado e foram observados valores entre -0,3 e-0,8MPa e-0,6 e-1,5MPa respectivamente. Os maiores valores de teores de prolina e de ABA correspondem a períodos de menor oferta de precipitação, entretanto, não há uma relação direta entre a síntese destes compostos $e$ as fases do florescimento avaliadas.

Palavras-chave: morfologia de gema, ácido abscísico, prolina, estresse hídrico, indução floral, floração uniforme.

\section{ABSTRACT}

Flowering on coffee plants involves several aspects from the plant as well as from the environment. Understanding these interactions can enhance the knowledge and promote better handling of the crop in field, mainly related to irrigation to promote synchronized flowering and consequently the uniform fruit maturation, lowering the production costs. The aim of the present study was to evaluate bud morphology, proline and abscisic acic biosynthesis on coffee plants under different environmental conditions in order to contribute to the knowledge in factors that influence flowering synchronization. Scanning electron microscopic was performed on buds of plagiotropic shoots weekly collected from November/04 to February/05. Predawn water potential and proline content analysis were carried out from July to September/05 using complete superior third expanded leaves from plagiotropic shoots of non and irrigated plants. Abcisic acid content was also evaluated in xylem sap and on flower buds. The results show alterations on bud morphology associated to the period of water deficit followed by precipitation and also, consequently, lower thermic amplitude. Regarding to the water potential, differences could be observed in the treatments having -0.3 and $0.8 \mathrm{MPa}$ for irrigated and -0.6 and $-1.5 \mathrm{MPa}$ for non-irrigated plants. The highest proline and abcisic acid content are related to dryer period, however there is no direct relationship between these biosynthesis compounds and the different flowering stages evaluated.

Key words: bud morphology, abscisic acid, proline, water deficit, floral induction, uniform flowering.

\section{INTRODUÇÃO}

O cafeeiro é uma espécie de grande importância econômica, sendo que alguns aspectos relacionados ao seu desenvolvimento reprodutivo são ainda pouco conhecidos. O processo do florescimento envolve tanto fatores internos da planta como fatores externos. Entretanto, são ainda escassas as informações sobre como esses fatores atuam na

'Departamento de Biologia/Fisiologia Vegetal, Universidade Federal de Lavras, (UFLA), Lavras, MG, Brasil. E-mail: marilzaagro@hotmail.com. *Autor para correspondência. 
formação das gemas florais. Pouco se sabe sobre a indução e o processo de desenvolvimento de gemas reprodutivas em Coffea arabica. A maioria das informações disponíveis abrange as fases mais avançadas de desenvolvimento das gemas florais (MAJEROWICZ \& SÖNDAHL, 2005).

Geralmente, associa-se ao florescimento do cafeeiro a necessidade de um déficit hídrico para a quebra de dormência do botão floral e, assim, o início da antese, contribuindo para uma floração mais homogênea (SOARES et al., 2005; MATIELLO et al., 2006). Alguns estudos mostram uma relação entre a florada principal e um período de estresse hídrico e ou uma queda de temperaturas, seguidas de suprimento de água via chuva ou irrigação (CAMARGO \& CAMARGO, 2001; SOARES et al., 2005).

O déficit hídrico pode alterar o metabolismo das plantas de diferentes maneiras. Entre elas, pode-se citar o mecanismo de ajustamento osmótico, que é caracterizado pela manutenção da turgescência celular, em baixos potenciais hídricos. A prolina é um dos compostos envolvidos nesse mecanismo que mais se correlaciona com o déficit hídrico em cafeeiros (DA MATTA et al., 1993; MAESTRI et al., 1995). É observado também, em condição de deficiência hídrica, um aumento da síntese do ácido abscísico (ABA) nas raízes, que é posteriormente transportado para a parte aérea, via xilema, após precipitação ou irrigação (HARTUNG et al., 2002).

O conhecimento de aspectos do florescimento, associado às condições hídricas do ambiente e da planta, pode contribuir para o desenvolvimento de técnicas de manejo, particularmente para a cultura irrigada. Um manejo mais adequado e racional da irrigação pode promover uma uniformização da floração e, como conseqüência, uma maturação mais homogênea dos frutos, minimizando assim, os custos de produção e agregando maior valor à qualidade da bebida. Com este trabalho objetivou-se avaliar alterações morfológicas de gemas, síntese de prolina e de ácido abscísico em plantas de cafeeiros em resposta a elementos meteorológicos, visando assim contribuir para o conhecimento de fatores que influenciam a uniformização da floração e, conseqüentemente, a uniformização da maturação de frutos no cafeeiro.

\section{MATERIAL E MÉTODOS}

O experimento foi conduzido em uma área experimental nas proximidades do Departamento de Agricultura, no campus da Universidade Federal de Lavras (UFLA), em Lavras, MG (latitude de $21^{\circ} 15^{\prime}$ S, longitude de $45^{\circ} 00^{\prime} \mathrm{W}$ e altitude média de $918 \mathrm{~m}$ ). O clima da região é Cwa, segundo a classificação climática de Köppen, com médias anuais, para precipitação e temperatura, de respectivamente, $1.530 \mathrm{~mm}$ e $19,4^{\circ} \mathrm{C}$ (BRASIL, 1992).

Foram estudadas plantas de uma lavoura cafeeira com, aproximadamente, dez anos de idade e que foi submetida a um processo de poda drástica (recepa), aos 65 meses de idade (setembro de 2001). A cultivar desta lavoura é a "Topázio MG-1190", implantada com espaçamento de 1,80 x 0,70.

As avaliações foram feitas em plantas nãoirrigadas e plantas irrigadas. O sistema de irrigação utilizado foi o de gotejamento, e a lâmina aplicada foi o equivalente a $80 \%$ do balanço entre a evaporação do tanque Classe A (ECA) e as precipitações ocorridas no período entre duas irrigações consecutivas $(80 \%$ ECA - precipitação). Os dados de precipitação e ECA foram obtidos na Estação Climatológica situada no Campus da UFLA, localizada a, aproximadamente, 500 metros da área experimental. As irrigações foram realizadas duas vezes por semana.

O solo da área experimental é classificado como Latossolo Vermelho distroférrico, com textura muito argilosa, plano e uniforme (EMBRAPA, 1999). O tipo de cultivo utilizado é o convencional, com adubação realizada em quatro vezes, de outubro a março, baseada na análise de fertilidade do solo e de acordo com o método da $5^{a}$ aproximação da Comissão de Fertilidade do Solo do Estado de Minas Gerais.

Para anatomia de gemas, foram utilizadas apenas plantas não-irrigadas, num total de 80 plantas. A coleta das gemas foi feita semanalmente, durante $o$ período de novembro de 2004 a fevereiro de 2005. As gemas foram coletadas a partir do ápice até o quarto nó dos ramos plagiotrópicos, posteriormente colocadas no fixador karnovisck e armazenadas em câmara fria a $7^{\circ} \mathrm{C}$ para posteriores avaliações. Na seqüência, as amostras foram lavadas com tampão cocodilato $(0,05 \mathrm{M})$ por três vezes, durante 10 minutos. Em seguida, foram transferidas para uma solução de tetróxido de ósmio $1 \%$ em água por 2 horas e, subseqüentemente, desidratadas em uma série de acetona $(30 \%, 50 \%, 70 \%$, $90 \%$ e $100 \%$, por três vezes) e depois levadas para o aparelho de ponto crítico. Os espécimes obtidos foram montados em suportes de alumínio "stubs". Após a montagem dos "stubs" as imagens das amostras foram registradas digitalmente, em aumentos variáveis, e gravadas no Software Photopaint, do pacote Corel Draw 9(ALVES, 2004).

O estado hídrico das plantas foi avaliado em um total de 40 plantas distribuídas em amostras de plantas irrigadas e não-irrigadas, por meio de medidas do potencial hídrico de base ( $\Psi_{\mathrm{w}}$ máximo), realizadas 
com auxílio de uma câmara de pressão (Soil Moisture Modelo 3005), em folhas do terceiro ou quarto nó, totalmente expandidas. As avaliações foram realizadas em quatro plantas por coleta (repetições), sorteadas na área experimental. As medidas foram realizadas com freqüência quinzenal, durante diferentes fases do florescimento (fase 1 - gema dormente; fase 2 - gema intumescida e fase 3 - com botões florais e flores abertas e com um pico de florada ao final dessa fase), definidas a partir do esquema proposto por PEZZOPANE et al. (2003).

Nas mesmas plantas que foram utilizadas para a avaliação do potencial hídrico, foram coletadas quatro folhas por planta, totalmente expandidas do terço superior da copa, sendo utilizadas quatro plantas aleatórias (repetições), com freqüência quinzenal, durante as fases mencionadas anteriormente. As folhas coletadas foram secas em estufa de circulação forçada de ar, a $72^{\circ} \mathrm{C}$, até atingir peso constante e, posteriormente, maceradas. Em seguida, 100mg de massa seca das folhas foram homogeneizados em $10 \mathrm{~mL}$ de ácido sulfosalicílico a $3 \%$. Essa mistura foi submetida à agitação por 60 minutos e filtrada em papel filtro. Os filtrados foram coletados e armazenados a $-20^{\circ} \mathrm{C}$. Para a quantificação do teor de prolina, utilizou-se uma metodologia obtida a partir do protocolo descrito por BATES (1973).

As coletas para a determinação do teor de ABA foram feitas mensalmente, de julho a setembro de 2005, abrangendo as diferentes fases do florescimento já citadas, realizadas em duas plantas (repetições), escolhidas aleatoriamente na área experimental. As gemas florais foram coletadas nos ramos plagiotrópicos de primeira e segunda ordem e armazenadas a $-80^{\circ} \mathrm{C}$. A seiva do xilema foi coletada na base dos ramos plagiotrópicos de primeira e segunda ordem, com o auxílio da câmara de pressão (Soil moisture - Modelo 3005), utilizando-se uma microsseringa, sendo coletado um volume de $400 \mu \mathrm{L}$, seguido de armazenamento a $-80^{\circ} \mathrm{C}$. O método de extração do ácido abscísico em gema floral foi adaptado a partir de BERRY \& BEWLEY (1992) e RAYKHEL et al. (1987). Para a avaliação na seiva foi utilizado material liofilizado, segundo recomendação de LOEWENSTEIN \& PALLARDY (2002). Na detecção de ácido abscísico, foram utilizados kits de ensaio imuno-enzimático (ABA Enzyme Immunoassay Test Kit - Sigma).

A análise de variância foi feita considerando-se um delineamento inteiramente casualizado, utilizando o teste $\mathrm{F}$ a $5 \%$ de probabilidade de erro, para verificar a significância por meio do software Sisvar (FERREIRA, 2006).

\section{RESULTADOS E DISCUSSÃO}

No mês de novembro, as gemas, independente da posição no ramo, não apresentaram modificações em sua estrutura (Figura 1A) em relação a uma estrutura característica de gema vegetativa. Apenas nas gemas do quarto nó do ramo plagiotrópico, no mês de dezembro, foi observada uma modificação morfológica, caracterizada por uma protuberância (Figura 1B). A modificação observada na estrutura da gema em dezembro indica que pode ser um indício de divisões celulares entre a zona central e o pith-rib, como citado por BERNIER (1988). Tais alterações podem ser tanto associadas ao crescimento como à diferenciação.

As condições meteorológicas (Figura 2) podem indicar que as modificações morfológicas observadas ocorreram em resposta a um período sem precipitações (seis dias) com elevada amplitude térmica (período seco), seguido de uma seqüência de dias chuvosos (dezesseis dias), em que observou-se um decréscimo da amplitude térmica. Em alguns estudos, entre eles JORDAN (1993), foi demonstrado que a diferenciação do meristema é asssociada ao estresse hídrico, que contribui para um aumento na concentração de amônia na planta, precedendo a biossíntese de etileno e, conseqüentemente, e diferenciação floral.

Em geral, estudos relacionados com floração do cafeeiro freqüentemente ressaltam a importância do fotoperíodo na indução floral. Entretanto, nesses estudos nem sempre a indução floral é observada no mesmo período do ano, indicando que o fator fotoperíodo pode não ser determinante para a indução floral (CAMARGO \& CAMARGO, 2001; MAJEROWICZ \& SÖNDAHL, 2005). Portanto, há necessidade de estudos que abordem aspectos desde alterações na estrutura anatômica das gemas à expressão gênica no processo de indução floral para a compreensão das interações entre fatores ambientais que determinam o florescimento no cafeeiro.

Os resultados de potencial hídrico obtidos durante o período experimental indicam diferenças entre os tratamentos hídricos, em que os maiores potenciais hídricos são observados no tratamento irrigado. Em média, os potenciais hídricos variaram entre $-0,3$ e -0,8MPa, para plantas irrigadas, e entre 0,6 e -1,5MPa, para plantas não-irrigadas (Figura 3). Percebe-se uma baixa variação do potencial hídrico em plantas irrigadas, o que mostra a eficiência da rega.

No período de julho, os valores de potencial hídrico medidos durante a fase 1 do florescimento, tanto para as plantas irrigadas como para as não-irrigadas, foram maiores que $-1.0 \mathrm{MPa}$, em resposta à ocorrência de precipitação (de 14,8mm), no dia 07/07 (Figura 3). Já para o início de agosto, foi observado o menor potencial hídrico de todo o período experimental para as plantas não-irrigadas $(-1,5 \mathrm{MPa})$. No entanto, esse valor é 


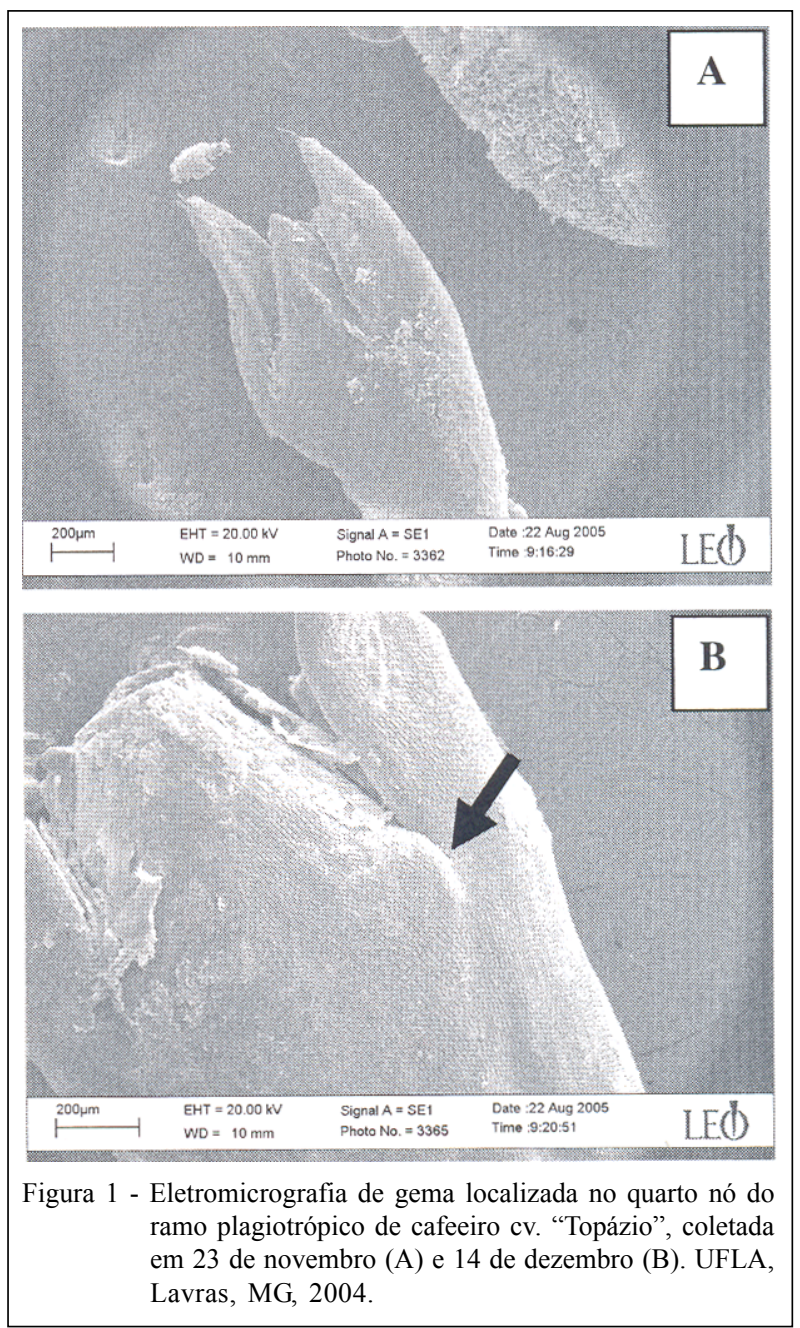

superior ao valor encontrado por Da MATTA et al. (1997) em que o cafeeiro apresentou-se sob deficiência hídrica severa, isto é, murcha visível nas primeiras horas da manhã e $\Psi_{\mathrm{w}}=-2,7 \mathrm{MPa}$.

Em meados de agosto (16/08), as gemas encontravam-se intumescidas (fase 2) e com alguns botões florais, para o tratamento irrigado, enquanto que, nas plantas não-irrigadas, foram observadas apenas as gemas intumescidas. Diante dos valores de potenciais hídricos verificados para as plantas irrigadas $(-0,6 \mathrm{MPa})$ não caracterizando, portanto, um déficit hídrico, pode-se associar a presença de botões florais à quebra da dormência das gemas, devido às baixas temperaturas que ocorreram no período.

No início de setembro (fase 2), observou-se uma maior porcentagem de flores no tratamento irrigado. Enquanto que no mesmo período, o tratamento não-irrigado apresentava apenas algumas plantas com botões florais, provavelmente em conseqüência da ocorrência de chuvas e aumento de temperaturas no período. No final de setembro, no tratamento nãoirrigado verificou-se um maior número de plantas com flores em um mesmo estádio de desenvolvimento, o que caracteriza uma sincronização da floração. Neste mesmo período as plantas do tratamento irrigado apresentavam-se com flores e botões florais em diferentes estádios de desenvolvimento, caracterizando uma menor uniformidade da floração.

A uniformidade floral observada para as plantas não-irrigadas pode ser atribuída ao fato de a florada ter ocorrido após um período de déficit hídrico, seguido de chuvas, o que propiciou um aumento significativo do potencial hídrico das plantas. Esse resultado é semelhante aos obtidos por OLIVEIRA (2003). Esses autores verificaram a presença de flores em uma freqüência maior nas plantas submetidas à irrigação, enquanto que nas plantas não-irrigadas a frequência foi menor. No entanto, foram observados picos de floradas mais uniformes nas plantas nãoirrigadas. Assim, pode-se inferir que o déficit hídrico 


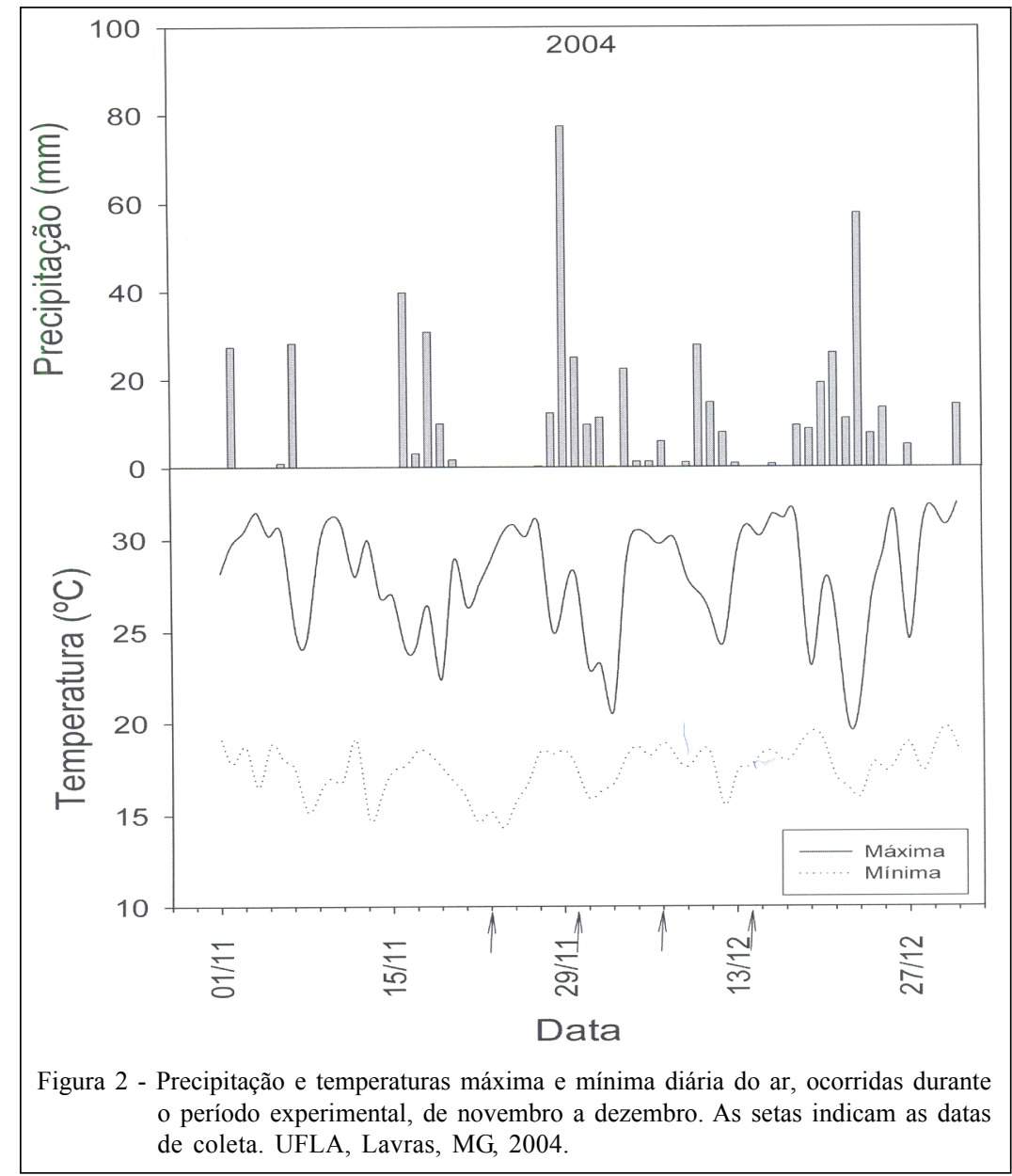

não é uma condição determinante para o cafeeiro florescer, mas necessária para uniformização da floração mais uniforme. MATIELLO et al. (2006) indica que a melhor forma de induzir a floração uniforme em cafeeiros é por meio da redução da quantidade de água, no período de julho/agosto, sem deixar os cafeeiros murcharem. Tal constatação reforça a necessidade do conhecimento da influência dos elementos meteorológicos no florescimento para o manejo da cultura do cafeeiro, principalmente em condições irrigadas.

Quanto aos teores de prolina, não foram observadas diferenças significativas entre os tratamentos (Figura 3). Isso pode ser devido ao fato de os potenciais hídricos foliares observados não terem atingido valores acentuados. A análise dos resultados mostra que, no período de julho até meados de agosto, época com poucas precipitações e baixas temperaturas, os teores de prolina são mais elevados. Após a ocorrência de precipitações, associada a um aumento da temperatura, no final de agosto até setembro, observaram-se menores teores em relação às avaliações anteriores, sendo mais evidente na fase final do experimento, quando ocorreram maior disponibilidade hídrica e, conseqüentemente, maiores potenciais hídricos, em ambos os tratamentos. Portanto, a diminuição do teor de prolina observada ao longo do período experimental foi mais associada ao aumento do potencial hídrico foliar que às variações das fases do florescimento. Assim, pode-se dizer que o déficit hídrico necessário para que ocorra a quebra de dormência das gemas não é muito severo, pois, como afirma SERRA \& SINCLAIR (2002), o ajustamento osmótico é um mecanismo que ocorre em condições de déficit hídrico acentuado.

Os teores de ABA foram maiores na seiva do xilema do que nas gemas florais (Figura 4). Isso pode ser devido ao fato de o ABA ser sintetizado nas raízes, induzido pelo déficit hídrico, ser transportado via xilema, justificando, assim, as maiores concentrações em relação a outras partes da planta, nas quais o mesmo é redistribuído. Para as gemas, na fase 1 e no final da fase 3, os maiores teores de ABA correspondem aos menores teores de ABA na seiva. A 


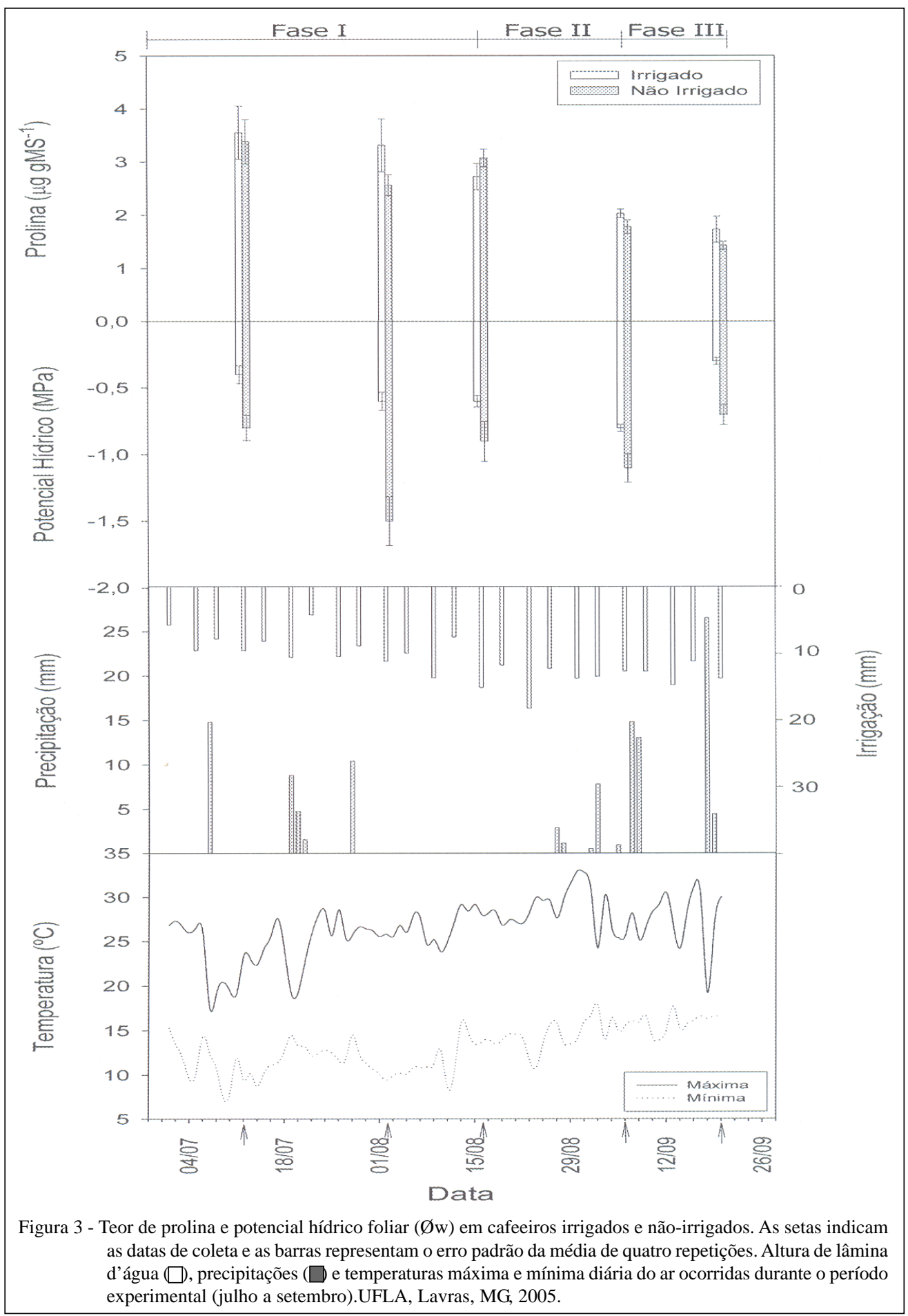

avaliação no início da fase 2 apresentou menores teores de ABA, o que caracteriza um comportamento inverso em relação ao teor de ABA na seiva. Em relação aos tratamentos, houve diferenças entre eles, sendo os maiores teores observados em plantas não-irrrigadas. No entanto, no período em que ocorreu um pico de floração (final da fase 3), quando foi observada maior freqüência de precipitações e maiores temperaturas, não foram observadas diferenças significativas entre os tratamentos.

A diminuição de ABA na seiva na fase 1 pode ser devido à precipitação que ocorreu no dia 07/

Ciência Rural, v.38, n.5, ago, 2008. 


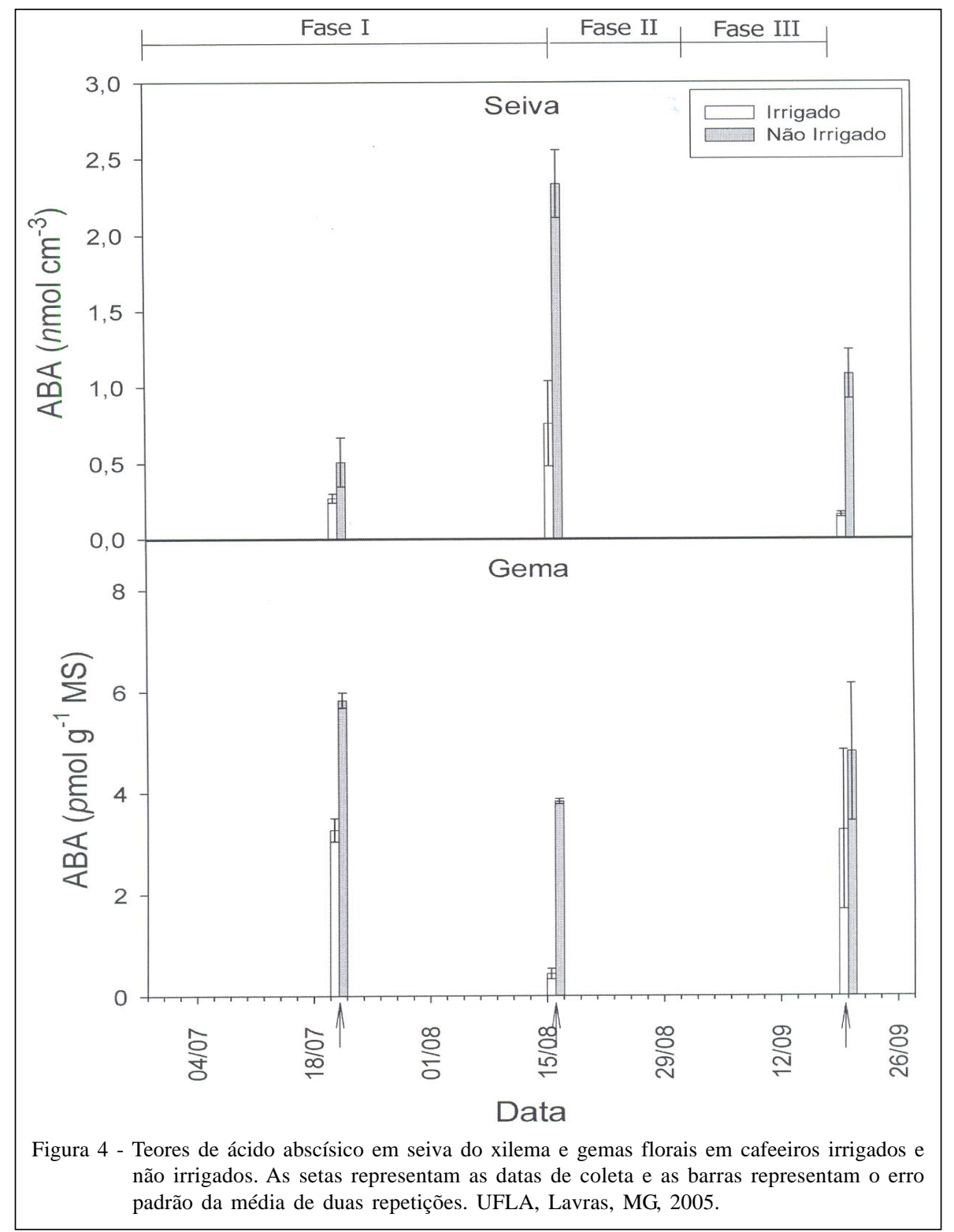

07, aumentando o potencial hídrico das plantas. Esse aumento de potencial hídrico se reflete no teor de ABA, primeiramente mais na seiva do xilema que em outras partes da planta, como observado também por BURSCHKA et al. (1983), em estudo de ABA em tecidos foliares e seiva do xilema, cujo resultado mostrou que a concentração de ABA no xilema é muito mais sensível à falta de água no solo que à concentração de ABA nas folhas. Observa-se também que houve relação direta entre a concentração de ABA na gema e o grau de dormência, confirmando os resultados de BROWING (1973). No período em que as gemas encontravam-se dormentes (julho), o teor de ABA foi maior em ambos os tratamentos, embora não tenha havido diferenças em relação à época em que ocorreu um pico de floração, o que pode ser atribuído, provavelmente, ao aumento deste hormônio na seiva no período de seca e que, posteriormente, foi transportado para a gema, aumentando o teor na gema e diminuindo na seiva. Este fato coincide com a ocorrência de precipitações, aumento de temperatura e de potencial hídrico e, conseqüentemente, a diminuição do teor de prolina e a maior porcentagem de flores abertas.

\section{CONCLUSÕES}

Alterações morfológicas da gema ocorrem após um período de déficit hídrico, seguido de

Ciência Rural, v.38, n.5, ago, 2008. 
precipitação e, conseqüentemente, uma menor amplitude térmica. A prolina não é um bom indicador fisiológico do estado hídrico no processo de florescimento do cafeeiro. A dormência da gema está associada positivamente ao teor de ABA, mas não se pode afirmar que a quebra de dormência esteja diretamente ligada à diminuição do teor de ABA. O teor de ABA é mais associado ao estado hídrico das plantas que às fases do florescimento.

\section{AGRADECIMENTOS}

Os autores agradecem ao apoio da CBP\&D-Café/ EMBRAPA CAFÉ, pelo auxílio financeiro.

\section{REFERÊNCIAS}

ALVES, E. Introdução à microscopia eletrônica de varredura. Lavras: UFLA/FAEPE, 2004. 43p. (Texto Acadêmico).

BATES, L.S. Rapid determination of free proline for waterstress studies. Plant and Soil, v.39, n.1, p.205-207, 1973.

BERNIER, G. The control of floral evocation and morphogenesis. Annual Review of Plant Physiology Plant Molecular Biology, v.39, p.175-219, 1988.

BERRY, T.; BEWLEY J.D. A role for the surrounding fruit tissue in preventing the germination of tomato (Lycopersicon esculentum) seeds. Plant Physiology, v.100, p.951-957, 1992

BRASIL. Ministério da Agricultura e Reforma Agrária. Secretaria Nacional de Irrigação. Departamento Nacional de Metereologia. Normais climatológicas - 1960-1991. Brasília, 1992. 84p.

BROWING, G. Flower bud dormancy in Coffea arabica L. I. Studies of gibberellin in flower buds and xylem sap and of abscísic acid in flower buds em relation to dormancy release. Journal of Horticultural Science, v.48, n.1, p.29-41, 1973.

BURSCHKA, C. et al. Diurnal variations in abscisic acid content and stomatal response to applied abscisic acid in leaves of irrigated and non-irrigated Arbutus unedo plants under naturally fluctuating environmental conditions. Oecologia, v.58, p.128131, 1983.

CAMARGO, A.P.; CAMARGO, M.B.P. Definição e esquematização das fases fenológicas do cafeeiro arábica nas condições tropicais do Brasil. Bragantia, v.60, n.1, p.65-68, 2001

DA MATTA, F.M. et al. Water relations of coffee leaves (Coffea arabica and Coffea canephora) in response to drought. Journal of Horticultural Science, v.68, n.5, p.741-746, 1993.

DA MATTA, F.M.; MAESTRI, M. Photoinhibition and recovery of photosynthesis in Coffea arabica and Coffea canephora. Photosynthetica, v.34, n.3, p.439-446, 1997.

EMPRESA BRASILEIRA DE PESQUISA AGROPECUÁRIA. Sistema brasileiro de classificação de solos. Brasília: Embrapa Produção de Informações / Rio de Janeiro: Embrapa Solos, 1999. 412p.

FERREIRA, D.F. SISVAR- Sistemas de análises de variância. Lavras: UFLA, 2006. (Software estatístico).

HARTUNG, W. et al. Abscisic acid in the xylem: where does it come from, where does it go to? Journal of Experimental Botany, v.53, n.366, p.27-32, 2002.

JORDAN, B.R. The molecular biology of flowering. Wallingford: CAB, 1993. 226p.

LOEWENSTEIN, N.J.; PALLARDY, S.G. Influence of a drying cycle on post-drought xylem sap abscisic acid an stomatal responses in young temperate deciduous angiosperms. New Physiologist, v.156, p.351-361, 2002.

MAESTRI, M. et al. Accumulation of proline and quaternary ammonium compounds in mature leaves of water stressed coffee plants (Coffea arabica e Coffea canephora). Journal Horticultural Science, v.70, n.2, p.229-233, 1995.

MAJEROWICZ, N.; SÖNDAHL M.R. Induction and differentiation of reproductive buds in Coffea arabica L. Brazilian Journal of Plant Physiology, v.17, n.2, p.247254, 2005.

MATIELLO, J.B. et al. Efeito do stress hídrico no abortamento e uniformização da floração em cafeeiros em região quente. In: CONGRESSO BRASILEIRO DE PESQUISAS CAFEEIRAS, 32. 2006, Poços de Caldas, MG. Anais... Poços de Caldas: CBP\&DCafé/EMBRAPA CAFÉ, 2006. 330p. p.30.

OLIVEIRA, L.A.M. Desenvolvimento vegetativo e reprodutivo do cafeeiro (Coffea arabica $\mathrm{L}$.) irrigado em diferentes épocas do ano. 2003 . 54f. Dissertação (Mestrado em Engenharia Agrícola. Irrigação e Drenagem) - Universidade Federal de Lavras, Lavras, MG.

PEZZOPANE, J.R.M. et al. Escala para avaliação de estádios fenológicos do cafeeiro arábica. Bragantia, v.62, n.3, p.499505, 2003.

RAYKHEL N.V. et al. An enzyme-immunoassay for quantitative analysis of abscisic acid in wheat. In: Molecular biology of plant growth control. New York: Alan R. Liss, 1987. p.197-207.

SERRA, R.; SINCLAIR, R.T. Osmolyte accumulation: can it really help increase crop yield under drought conditions? Plant Cell Environnmental, v.25, p.333-341, 2002.

SOARES, A.S. et al. Irrigação e fisiologia da floração em cafeeiros adultos na região da zona da mata de Minas Gerais. Acta Scientiarum Agronomy, v.27, n.1, p.117-125, 2005. 